\title{
STUDY OF FLORISTIC STRUCTURE OF THE TERRITORY USING FAMILY RANGE IN THE SOK RIVER BASIN (SAMARA REGION, ZAVOLZHYE, FOREST-STEPPE ZONE)
} (C) 2016

A.V. Ivanova, candidate of biological sciences, researcher of the Laboratory of Problems of Phytodiversity

N.V. Kostina, candidate of biological sciences, senior researcher

of the Laboratory of Modeling and Management of Ecosystems

Institute of Ecology of the Volga River Basin of Russian Academy of Sciences, Togliatti (Russia)

Abstract. Ecological approach to the study of flora implies an integral flora unit called elementary flora (EF), which is usually regarded as the elementary unit of floristic division. Identification of the minimum-range of EF is prerequisite for the research of flora of any territory. The aim of this research is to identify the number of EF in the research area (floral patterns) by comparing the values of certain parameters of the family range of flora in four minimum-ranges.

The basin of the river Sok is the research area. Its landscape zoning varies in different literature sources. Florae of the four minimum-range habitats are formed on territorial basis with reference to the existing floristic descriptions. The following parameters of the family range of flora in four minimum-ranges were used: establishment of the order of the first triad of families depending on number of species in a sample, percentage of monotypic families and percentage of species in the top ten families.

The considered values of florae parameters in the sample areas corresponding to the minimum-range habitats show a certain degree of similarity. The largest differences were observed in the study of the formation of top three leading families, depending on the number of species. This indicator reflects the peculiarities of individual sample areas due to the variety of intra-landscape. The authors reach a conclusion concerning the conditional affiliation of the researched territory to one EF. The conclusion is based on the analyzed parameters of the family range of flora of all minimum-ranges as well as their floristic descriptions.

Keywords: elementary flora (EF), level of species richness, EF minimum-range, sample area, landscape flora, the Sok river basin, Samara region, family range, triad of leading families, proportion of monotypic families.

УДК581.9:581.524

\section{СИНАНТРОПНЫЕ РАСТЕНИЯ КАК ПОКАЗАТЕЛЬ ЭКОЛОГИЧЕСКОГО СОСТОЯНИЯ ГОРОДА САМАРЫ}

(c) 2016

Н.В. Иванова, кандидат биологических наук, доцент кафедры коммерции, сервиса и туризма Самарский государственный экономический университет, Самара (Россия)

Аннотация. Данная статья посвящена анализу синантропной флоры г. Самары. В ней рассмотрена история изучения флоры города Самары, а также говориться, что судить об экологическом состоянии города Самары можно по процессу и степени синантропности. При изучении урбанофлор понятие «синантропная флора» и её элементы определяются у разных авторов по-разному. Вопросами терминологии занимались О.П. Виньковская, Е.П. Гнатюк, Г.С. Антипина, К.В. Качкин, И.Г. Соколова, Т.В. Астахова, Т.А. Терехина. В понимании автора статьи синантропная флора состоит из адвентивных культурных, адвентивных сорно-рудеральных и апофитных видов.

В условиях возрастающего антропогенного изменения всё более актуальным становится процесс синантропизации растительного покрова. А также в данной статье описан состав синантропной фракции урбанофлоры Самары. Автором отмечено, что синантропной фракции наблюдается значительное снижение доли однодольных растений, а также лидирование адвентивных видов, при этом в состав флоры входят лесостепные бореальные, неморальные и плюризональные растения. При анализе синантропного компонента флоры были вычислены такие показатели, как индекс синантропизации флоры индекс адвентивности, индекс апофитности и индекс окультуренности. В конце работы был сделан вывод о том, что синантропизации привёл к уменьшению разнообразия флоры.

Ключевые слова: город Самара, флора, синантропные растения, синантропная флора, экологическое состояние городской среды, урбанофлора, индекс синантропности, индекс адвентации, индекс апофизации, индекс окультуренности, адвентивные культурные виды, адвентивные сорно-рудеральные виды, апофиты

Об экологическом состоянии города Самары можно судить по процессу и степени синантропности, а также по наличию и распространению в городе аборигенной флоры естественных природных комплексов, в том числе редких для города растений. Соотношение синантропных и раритетных видов (в пользу первых) является результатом урбанизации - многовекового освоения городской территории. В условиях возрастающего антропогенного изменения всё более актуальным становится процесс синантропизации растительного покрова. Для оценки масштабов и возможных послед- ствий синантропизации необходим мониторинг данного процесса [1]. Выявление синантропных видов - один из путей решения данной задачи.

Сведения о флоре и растительности города Самары незначительны в своём объёме и имеют отрывочный характер. Первой флористической сводкой можно считать «Дневники Самарской природы 1916 года Н.Г. Щербиновского. В начале прошлого века натуралист Н.Г. Щербиновский проводил фенологические наблюдения в пригороде Самары [2,3]. Он обследовал Волжский склон, который ныне лежит в пределах гра- 
ниц города Самары. В ходе своих исследований Н.Г. Щербиновский составил флористический список, который насчитывает более 230 видов. В тридцатые годы XX века флора пригородной зоны Куйбышева (Самары), которая ныне является городской территорией, тоже была объектом флористических исследований. Например, И.С. Сидорук изучал флору Зубчаниновского свинсовхоза и другие территории пригородной части Куйбышева $[4,5]$. В работе «Растительность Куйбышевской пригородной зоны» можно найти флористический список, который составляет 379 видов из 242 родов и 65 семейств [6].

В 80-е годы XX века ботаниками госуниверситета было проведено обследование дикорастущей флоры городов Куйбышева (Кировский, Куйбышевский и Промышленный районы), Тольятти, Сызрани и Похвистнево [7]. Куйбышевский район был обследован ботаниками Г.П. Игошиным и О.А Мозговой в 1993 году. По результатам обследования была издана статья «Флора Куйбышевского района г. Самары», где приводится список растений (из 379 наименований видов, относящихся к 63 семействам), произрастающих в Засамарской слободе. Авторы статьи сопоставили современную флору со списком И.С. Сидорука, а также провели сравнение биоморфного состава. В результате исследователи выявили, что 20 видов за 90 лет исчезли с этих мест произрастания. Г.П. Игошин и О.А.Мозговая указали ведущие семейства: Asteraceae, Lamiaceae, Poaceae, Fabaceaee, Brassicaceae, Rosaceae, Chtmopodiaceae, Caryophyllaceae, Ranunculaceae, Cyperaceae [6].

Из современных исследований по изучению флоры и растительности населенных пунктов Самарской области и г. Самары большой интерес представляют некоторые фундаментальные работы. Одна из них - «Сосудистые растения Самарской области» [7]. В данной работе приводится изучение местообитания 7 видов растений города Самара: Sisymbriumirio L., Xanthoxalis fontana (Bunge) Holub, Geranium depillatum (Somm. Et Levier) Grossh., Stachys sieboldii Miq., Elytrigia trichophora (Link) Nevski, а также трех видов, которые произрастают вблизи города - Batrachium rionii (Laagg.) Nym. (отмечен в окрестностях Куйбышева, 1961 г.), Consolida orientalis (J. Gay) Schreding (отмечен в пригородном лесу близ Самары, 2000), Ranunculus polyphyllus Waldst. et Kit. et Willd. (окрестности Куйбышева, 1957) [8]. Так же большой интерес вызывают результаты работы Л.М. Кавеленовой. В своей работе изыскатель анализирует и сопоставляет флористические списки Н.Г. Щербиновского (1916 г.) и авторские (1990-2002 гг.). Автором исследованы волжский склон, ЦПКиО им. Ю. Гагарина, некоторые улицы города Самары. В совокупности на данной территории произрастает 335 видов сосудистых растений. Это на 105 видов больше, чем в списке 1916 года. Согласно научным данным, за последние 90 лет исчезли 11 видов растений - Valeriana officinalis L., Gentiana cruciata L., Iris sibirica L., Poligata vulgaris L., Lilium martagon L., Clematis integrifolia L., Tulipa biebersteiniana L., Gladiolus imbricatus L., Agrostemma githago L. и Vaccaria hismanica (Mill.) Reusehert. Интересен и тот факт, что изыскатель в Октябрьском районе нашёл Aegilops culindrical Host [9].

Изучением одного из элементов урбанофлоры прибрежно-водных и водных растений Самары занималась В.В. Соловьева. По её мнению, пруды г. Сама- ры достаточно хорошо изучены. Гидроботаником проведён анализ динамики флоры прудов города Самары за последние десятилетия конца прошлого века. Последние опубликованные работы по гидроботанике Самары посвящены флористическим находкам и мониторингу искусственных прудов, редким явлениям гидрофитов в прудах города. В 2000 году впервые для Самары был найден африканский адвент - Pistia stratiotes L. $[10,11,12]$. Так же изучением флористического компонента растительного мира г. Самары занимались С.А. Розно [13] и Т.Б. Матвеева [14]. Но в своих работах вышеназванные исследователи не выделяют такую фракцию урбанофлоры как синантропная флора.

Много спорных вопросов при изучении урбанофлор касаются терминологии, в особенности синантропной. Понятие «синантропная флора», элементы (виды) входящие в ее состав определяются у разных авторов поразному [15-19]. В нашем понимании состав синантропной флоры входят адвентивные культурные виды, адвентивные сорно-рудеральные, апофиты, в том числе устойчивые к антропизации. В данном случае культурные виды - это многолетние культивируемые растения, а так же «беглецы из культуры.

При анализе урбанофлоры Самары выделилась особая фракция, которую назвали «ядром» урбанофлоры Самары, т.е. в состав ядра флоры входят такие виды растений, которые встречаются во всех типах местообитаний растений. Изучая более детально флору города, мы выделили 3 типа (зоны) местообитаний растений. Урбанофлора включает виды, произрастающие на участках естественного, искусственного и стихийного типов происхождения местообитаний растений.

В состав флоры города входят виды: 1) произрастающие только в одной из зон местообитаний растений; 2) произрастающие только на участках двух типов местообитаний и 3) виды, являющиеся «ядром» урбанофлоры, т.е. встречающиеся во всех трёх типах местообитаний растений города Самара [15].

Флора «ядра» насчитывает 197 видов, 144 рода и 44 семейства. Эти виды составляют $23 \%$ от урбанофлоры. Около половины видов, а именно $49,5 \%$ - многолетние травы, 27,5\% - однолетники, 11,2\% двулетники. Древесно-кустарниковые и лиановидные растения составляют $23 \%$ от общей флоры. Все виды из данной фракции имеют широкий спектр распространения. Большинство видов, а именно 64 (32,5\%) являются адвентивными видами; 46 - лесостепными (23,3\%), 42 - бореальными $(21,4 \%) ; 29$ - неморальными $(14,7 \%)$ и 5 плюризональными (2,5\%). Если рассматривать долготно-географические группы, то здесь тоже не наблюдается широкого разнообразия. Все они относятся к 12 группам: евроазиатская и европейская группы охватывают по 46 видов (по 23,3\% от общей флоры); азиатская и ирано-туранская - по 22 вида (по 11,2\%); голарктическая - 20 (10,1\%); евро-юго-западно-азиатская - 13 (6,6\%); плюрирегиональная - 10 (5\%); североамериканская - 8 (4\%); евро-сибирская - 4 (2\%); средиземноморская - $3(1,5 \%)$; сибирская и центральноамериканская - по 1 (по 0,5\%). Как видно из этих данных в числе «ядра» урбанофлоры преобладают растения с широким ареалом распространения.

Большинство видов, а именно 66 являются адвентивными; 46 - лесостепными (23,3\%), 42 - бореальными $(21,4 \%) ; 29$ - неморальными $(14,7 \%)$ и 5 - плюризональными (2,5\%). Лидирующими среди аборигенных видов фитоценотическими группами являются луговые 
растения - 36 (18,3\% от числа видов «ядра»), лесостепные - 33 (16,7\%), лесные - 22 (11,2\%), лугово-степные - 8 (4\%), степные - 6 (3\%), прибрежно-водные и водные - 6 (по 3\%) и прочие. Данные виды оказались наиболее распространенными и более устойчивыми к процессу урбанизации. Аборигенные виды «ядра» урбанофлоры отнесены в качестве апофитных растений к синантропной фракции.

В урбанофлоре Самары автором было отмечено 391 синантропный вид, относящийся к 236 родам и 66 семействам. Такое количество видов составляет 46\% от урбанофлоры г. Самары. К заносным культурным растениям относятся 113 видов; к заносным сорнорудеральным - 147; к апофитам - 131 .

В синантропной фракции наблюдается значительное снижение доли однодольных растений, которая составляет 47 видов (12\% от синантропных видов). Двудольные в себе содержат 335 видов (85,9\%). Отношение однодольных к двудольным в урбанофлоре составляет $1: 4,6$, а в синантропной - фракции 1:7,2. Все эти явления указывают на процесс урбанизации и ведут к снижению биоразнообразия территории, к унификации видового состава разных урбоэкосистем, к снижению уровня стабильности и продуктивности растительного покрова. Снижение доли однодольных в урбанофлоре характерно для многих крупных городов России.

При анализе синантропного компонента флоры используются следующие показатели: 1) индекс синантропизации флоры - отношение синантропных видов к общему числу видов флоры (для Самары - Is=0,46); 2) индекс адвентивности - отношение адвентивных видов к общему числу синантропных видов $(\mathrm{Iad}=0,38) ; 3)$ индекс апофитности, или апофизации - отношение апофитов к общему числу синантропных видов $($ Iap=0,23) и индекс окультуренности - доля культурных видов $(\mathrm{Ik}=0,29)$. Самарские индексы апофизациии окультуренности близки к показателям Іари Ik города Пскова [18]. Индекс синантропизации флоры города Самары достаточно типичен и близок к показателям городов европейской части России. Но при этом для урбанофлоры Самары характерен высокий уровень синантропизации (32,4\%). Данный уровень на 2,4\% превысил уровень синантропизации, при котором утрачивается зональная фитоценотическая структура.

Интенсивный обмен видами растений и сходство условий обитания в городах привели к тому, что одни и те же синантропные виды прижились в городах, расположенных в разных природных зонах [1]. Формирование городских флор - яркий пример процесса современного изменения растительного мира под влиянием антропогенных факторов. Процесс синантропизации привёл к уменьшению разнообразия флоры.

\section{СПИСОК ЛИТЕРАТУРЫ:}

1. Абрамов Н.В. Флора республики Марий Эл: инвентаризация, анализ, районирование, охрана и проблемы рационального использования её ресурсов: дис. ... д-ра. биол. наук. Пермь, 2001. 60 с.

2. Щербиновский Н.Г. Дневники Самарской природы 1916 года. Самара: Типография Самарского Губернского Совета Народного Хозяйства. № 2. 1919. 146 с.

3. Кавеленова Л.М. Проблемы организации системы фитомониторинга городской среды в условиях лесостепи. Самара: Самарский университет, 2003. 124 с.

4. Сидорук И.С. Отчет геоботанического свинсовхоза Самарского района Средне-Волжского края. Самара, 1932. $25 \mathrm{c}$.
5. Сидорук И.С. Растительность Куйбышевской пригородной зоны / Известия Куйбышев. сельскозозяйственного института. Вып. 1. Куйбышев: КСХИ, 1935. C. 63-91.

6. Игошин Г.П., Мозговая О.А. Флора Куйбышевского района г. Самары // Флористические ьсследования в Поволжье и на Урале. Самара: Изд-во «Самарский университет», 1993. С. 36-43.

7. Игошин Г.П., Киселёв О.Б., Мозговая О.А., Тихомирова Н.В., Федотова Е.Ф. Флора сосудистых растений городов Куйбышевской области // Проблемы изучения синантропной флоры СССР. М: Наука, 1989. С. $56-58$.

8. Сосудистые растения Самарской области / под ред. А.А. Устиновой, Н.С. Ильиной и др. Самара: ООО «ИПК «Содружество», 2007. 400 с.

9. Кавеленова Л.М. Экологические основы теории и практики системы фитомониторингаурбосреды в условиях лесостепи: дис. ... д-ра биол. наук: 03.00.16: Самара, 2003399 c.

10. Соловьева В.В., Саксонов С.В. Флористический мониторинг малых искусственных водоёмов Самарской области (2001-2005 гг.) // Поволжский экологический журнал. Саратов: ИПЭЭ РАН, 2006. № 2/3. С. 188.

11. Соловьёва В.В., Дашутин А.П. Динамика флоры прудов города Самары за последние двадцать лет // Взаимодействие человека и природы на границе Европы и Азии. Тезисы докладов конференции 18-20 декабря 1996 года. Самара, 1996. С. 101-102.

12. Соловьева В.В. Флористические находки и редкие явления биоэколо-гии гидрофитов в прудах г. Самара // Фитообразование Восточной Европы. 2007 № 2. C. 174-180.

13. Розно С.А. Эколого-биологический анализ итогов интродукциидревесных растений в лесостепи Среднего Поволжья: автореф. дис. ... канд. биол. наук: 03.00.16. Самара, 2005. 20 c.

14. Матвеева Т.Б. Комплексная характеристика пригородных лесов окрестностей Самары: дис. ... канд. биол. наук: 03.02.08. Саратов, 2015. 268 с.

15. Виньковская О.П. Флора Иркутской городской агломерации и ее динамика за последние 125 лет: дис. ... канд. биол. наук. Иркутск, 2005. 241 с.

16. Гнатюк Е.П., Антинина Г.С. Методы сборов и анализов флористических данных // Методы полевых и лабораторных методов исследований растений и растительного покрова. Петрозаводск: Карельский научный центр РАН, 2001. С. 126-146.

17. Качкин К.В. Синантропная растительность правобережья г. Новосибирска: дис. ... канд. биол. наук. Новосибирск, 2005. 158 с.

18. Соколова И.Г. Синантропная флора города Пскова: дис. ... канд. биол. наук. СПб, 2006. 203 с.

19. Астахова Т.В., Терехина Т.А. Растительность г. Рубцовска и его окрестностей // Ботан. исследования в азиатской России: материалыХІ съезда Русского ботанического общества. (Новосибирск-Барнаул, 18-22 августа 2003 г.). Т. 2. Барнаул: Изд-во «Азбука», 2003. C. $305-306$.

20. Иванова Н.В. Основные типы местообитаний растений урбоэкосистемы Самары // Известия Самарского научного центра РАН. Самара: АНО «Из-во СНЦ PAH»,2010, T. 12. № 1. C. 86-91. 


\section{SYNANTHROPIC PLANTS AS INDICATORS OF THE ECOLOGICAL STATE OF CITY OF SAMARA}

(C) 2016

N.V. Ivanova, candidate of biological sciences, associate professor of the Chair of Commerce, Service and Tourism Samara State University of Economics, Samara (Russia)

Abstract. This article focuses on the analysis of synanthropic flora of Samara. It surveys the history of the research of the flora of the city of Samara, and states that it is possible to base the estimation of the ecological condition of the city of Samara on the process and degree of synanthropy. When studying urbanoflorae different authors define the concept of synanthropic flora differently. O.P. Vinkovskaya, E.P. Gnatyuk, and G.S. Antipina, K.V. Kachkin, I.G. Sokolova, T.V. Astakhova, T.A.Terekhina dealt with issues of terminology. The author believes that the synantropic flora consists of adventitious cultivated plants, adventitious ruderal weeds and apofyte types.

In the conditions of the increasing anthropogenous change the process of synanthropization of the vegetable cover becomesquite urgent. The article describes the structure of the synanthropic fraction of the urban flora of Samara. The author notes that in the synanthropic fraction the share of monocotyledonous plants has considerably decreased, and that the adventitious species prevail, the flora being made up by forest-steppe boreal, nemoral and multizone plants. In the analysis of the synanthropic component of the flora such indicators as the flora synanthropy index, the adventivity index, index of the apofyteness and the index of cultivation have been calculated. The author comes to the the conclusion that synanthropy causes reduction of the flora variety.

Keywords: Samara, flora synanthropic plants, synanthropic flora, ecological state of the urban environment, urban floras, synanthropy index, adventity index, apofyteness index, cultivation index, adventitious, cultivated species, adventitious weed-ruderal species, apophytes.

УДК 57.044

\section{СОДЕРЖАНИЕ ТЯЖЁЛЫХ МЕТАЛЛОВ В ПОЧВЕННОМ ПОКРОВЕ В УСЛОВИЯХ ТЕХНОГЕНЕЗА}

(C) 2016

И.В. Казанцев, кандидат биологических наук, декан естественно-географического факультета

Т.Б. Матвеева, кандидат биологических наук, старший преподаватель кафедры биологии, экологии и методики обучения Самарский государственный соџиально-педагогический университет, Самара (Россия)

Аннотаџия. В данной статье рассматривается загрязнение почв тяжёлыми металлами в условиях техногенного воздействия. Описываются способы и пути поступления поллютантов в почвы, а также особенности их накопления в почвах, располагающихся в отводе железной дороги. Рассматривается роль придорожных лесных полос на характер распространения поллютантов. Определение содержания тяжёлых металлов в почвах осуществлялось рентгенофлуоресцентным методом. В работе представлены результаты сравнения загрязнения почв тяжелыми металлами по сравнению с кларковым значением, предельно-допустимой концентрацией, региональным фоновым уровнем. Изучение содержания тяжелых металлов проводилось на участке Куйбышевской железной дороги направления Самара-Сызрань в почвах полосы отвода, а так же в пригородных лесах и городских парках г. Самары (Ботанический сад, Загородный парк). Данные территории являются участками, подвергающимися значительному техногенному воздействию. Проведенные исследования показали, что на данных территориях наблюдается повышенное содержание ряда тяжёлых металлов в почвах, из которых основными элементами присутствующими в техногенных потоках загрязнения являются медь, никель, хром, цинк и свинец. Данный результат не противоречит стандартной экологической ситуации. Полученные материалы могут служить основой для дальнейшего мониторинга как пригородных лесов и зелёной зоны города Самары, так и транспортных сооружений.

Ключевые слова: тяжёлые металлы, поллютанты, элементный ряд накопления, предельно допустимая концентрация, региональный фоновый уровень, пригородные леса, лесополоса, экологический мониторинг, почвенный мониторинг, железная дорога, Куйбышевская железная дорога, город Самара, Самарская область.

Основной причиной ухудшения состояния урбанизированных территорий является техногенное воздействие. Самарская область является важным промышленным регионом, для которого проблема загрязнения окружающей среды является весьма актуальной. Выбросы промышленных предприятий, энергетика, сжигание отходов, минеральные удобрения, сточные воды, железнодорожный и автомобильный транспорт являются основными источниками поступления в почвенный покров загрязнителей, в том числе и целого комплекса тяжелых металлов, считающихся наиболее токсичными из поллютантов.
В сложившихся условиях все возрастающей антропогенной нагрузки на природную среду происходит резкий рост уровня её загрязнения и все большую роль в этом оказывает развитие транспортных коммуникаций и в частности железная дорога $[1,2,3,4,5]$. Их влияние на компоненты природы многоаспектно, среди которых значимым и опасным является загрязнение тяжелыми металлами. Их миграция и накопление в компонентах экосистем зависят как от ряда природных факторов, так и от интенсивности и характера техногенеза. Железнодорожная дорога является линейно сложным, системно работающим технико-технологическим 